\title{
Guizhi-jia-houpu-xingzi decoction attenuates ovalbumin- induced allergic asthma via regulation of Toll-like receptor signal pathway
}

\author{
Chuan Zheng, Yongxiang Gao, Jing Zhao, Xinglong Liu, Wen Fu* \\ Chengdu University of Traditional Chinese Medicine, Chengdu 610075, PR China
}

*For correspondence: Email: fuwen@cdutcm.edu.cn; Tel: +86-028-61800049

Sent for review: 6 February 2017

Revised accepted: 27 April 2017

\begin{abstract}
Purpose: To study the effect of Guizhi-jia-houpu-xingzi $(G H X)$ on ovalbumin-induced allergic asthma in rats.

Methods: An animal model of allergic asthma ( $A A)$ in rats was established by intraperitoneal injection (ip) of ovalbumin (OVA). Thereafter, GHX (375 mg/kg) was administered orally for 7 days. Pulmonary function, inflammatory cells, immunoglobulin $E$ (Ig) E, interleukin-4 (IL)-4 and interferon- $y$ (IFN)-y in serum and bronchoalveolar lavage fluids (BALF) were determined. Furthermore, mRNA expressions of Toll-like receptors (TLRs) signal pathway was determined using real time polymerase chain reaction PCR (q-RT-PCR).

Results: GHX $(375 \mathrm{mg} / \mathrm{kg})$ significantly decreased respiratory rate $(p<0.01)$ and Penh value $(p<0.05)$ when compared with $A A$ rats. The inflammatory cells $(p<0.01)$ and levels of IL-4 $(p<0.01)$ and IgE $(p$ $<0.01)$ were significantly decreased by GHX treatment when compared with AA rats; whereas IFN- $y$ ( $p$ $<0.05$ ) was significantly increased. Furthermore, GHX significantly decreased the mRNA expressions of GATA binding protein $(G A T A)-3(p<0.01)$, TRL-2 $(p<0.01)$, TRL-4 $(p<0.01)$, myeloid differentiation factor 88 (MyD88) $(p<0.01)$, TNF receptor associated factor 6 (TRAF6) $(p<0.01)$ and $\beta$-arrestin $(p<$ 0.01 ) in lung tissues, relative to $A A$ rats. However, GHX treatment led to significant up-regulation of mRNA expression of $T$-bet $(p<0.01)$.

Conclusion: These results demonstrate that GHX possesses a potential for treating allergic asthma via regulation of Toll-like receptor (TLR) signal pathway. They also provide a scientific basis for the probable use of GHX in clinical treatment of allergic diseases in future.
\end{abstract}

Keywords: Guizhi-jia-houpu-xingzi decoction, Ovalbumin, Allergic asthma, Toll-like receptor

Tropical Journal of Pharmaceutical Research is indexed by Science Citation Index (SciSearch), Scopus, International Pharmaceutical Abstract, Chemical Abstracts, Embase, Index Copernicus, EBSCO, African Index Medicus, JournalSeek, Journal Citation Reports/Science Edition, Directory of Open Access Journals (DOAJ), African Journal Online, Bioline International, Open-J-Gate and Pharmacy Abstracts

\section{INTRODUCTION}

Current epidemiologic studies have revealed that the prevalence and incidence of allergic diseases (especially allergic asthma) have increased sharply world-wide [1,2]. Allergic asthma is a complex chronic airway inflammatory reaction mediated by mastocytes, eosinophils and Tlymphocyts [3,4]. Recent reports showed that morbidity from allergic asthma is approximately
$18 \%$ in Western counties, and that there are about 300 million allergic asthma patients in the world, while over 180 thousand patients die yearly from the disease $[5,6]$. Therefore, allergic asthma is a serious threat to public health.

Currently available drugs for treating allergic asthma are mainly bronchodilators, antiinflammatory drugs, leukotriene receptor antagonists and immune-modulators, such as 
theophylines, immunoglobulin (Ig) E and glucocorticoids $[7,8]$. However, these drugs just alleviate only the symptoms of allergic asthma without providing radical cure [9]. In addition, longtime use of these drugs might result in some serious side-effects, such as gastrointestinal discomfort, drug dependency, and blood capillary injury $[8,10]$. Thus, it has become necessary to find some new sources of reliable drugs of low toxicity for curing allergic asthma.

Guizhi-jia-houpu-xingzi decoction (GHX) is a popular traditional Chinese formula used which produces good therapeutic effects on allergic asthma in clinics [11]. It has been reported that GHX down-regulated TNF- $\alpha$ in bronchoalveolar lavage fluids (BALF) of experimental asthma guinea pig, indicating that $\mathrm{GHX}$ may have potential benefits for allergic asthma patients [12]. However, so far, there are no systemic animal studies and its mechanism of action extensively limits the clinical application of GHX in the treatment of allergic asthma or other allergic diseases. In the present study, an experimental allergic asthma rat animal model was established induced by induction with ovalbumin (OVA). Based on the animal model, the therapeutic effects of $\mathrm{GHX}$ were evaluated and the possible pharmacological mechanisms were explored.

\section{EXPERIMENTAL}

\section{Chemicals and reagents.}

Ovalbumin (OVA) was purchased from SigmaAldrich Co. (Shanghai, China). Aminophylline (ANP) was purchased from Southwest Pharm. Ltd. (Chongqing, China). Trizol reagents were products of Invitrogen Co. (Carlsbad, CA, USA). Rat Elisa kits for secretory immunoglobulin A (slg A), immunoglobulin $E$ (lgE), interleukin-4 (IL-4) and interferon- $\mathrm{Y}$ (IFN-y) were products of Neobioscience Co. (Shenzhen, China). HiScript 1st Strand cDNA Synthesis kits and SYBR Green Master Mix were products of Vazyme Biotech. (Nanjing, China). Hematoxylin and eosin (H \& E) was purchased from the Baso Biotech. (Zhuhai, China). All primers used in the study were designed by Primer-Express v3.0 and synthesized by Sangon Biotech. (Shanghai, China, Table 1).

\section{Animals}

Male Sprague-Dawley (SD) rats (3 - 4 weeks old, $200 \pm 20 \mathrm{~g}$ ) were purchased from the Dashuo Laboratory Animal Co. Ltd (Chengdu, China) and were kept in a temperature $\left(22 \pm 2{ }^{\circ} \mathrm{C}\right)$ and humidity $(40-60 \%)$ controlled room with food and water provided ad libitum. All the animal experimental protocols were according to the International Principles of Laboratory Animal Care [13] and approved by the Ethics Committee for Laboratory Animal Experimentation of Chengdu University of Traditional Chinese Medicine (approval no. 2014KL-061).

\section{Preparation of GHX extracts}

All the crude TCMs in GHX were decocted with pure water. The TCMs were Cinnamomi ramulus (9 g), Magnoliae officinalis cortex $(6 \mathrm{~g})$, Armeniacae semen amarum (6 g), Paeoniae radix alba (9 g), Glycyrrhizae radix rhizoma $(6 \mathrm{~g})$, Zingiberis rhizoma recens $(9 \mathrm{~g})$ and Jujubae fructus $(15 \mathrm{~g})$.

Table 1: Primers used

\begin{tabular}{lll}
\hline Gene & & Sequence \\
\hline \multirow{2}{*}{ GATA-3 } & Forward & 5'-CTGGAGGAGGAACGCTAA-3' \\
& Reverse & 5'-GTCTGTTAATATTGTGGAGTTTG-3' \\
T-bet & Forward & 5'-CCATTCCTGTCCTTCACT-3' \\
& Reverse & 5'-CCACCAAGACTACATCCA-3' \\
TLR-2 & Forward & 5'-GTTGCGTTACATCTTGGA-3' \\
& Reverse & 5'-GGAATACACAGTGCTCAG-3' \\
TLR-4 & Forward & 5'-CAGCTCGTTTCTCACCCAGT-3' \\
& Reverse & 5'-TGTATCGGTGGTCAGTGTGC-3' \\
MyD88 & Forward & 5'-CGACGCCTTCATCTGCTA-3' \\
& Reverse & 5'-GCCGATAGTCTGTCTGTTCT-3' \\
TRAF6 & Forward & 5'-CAGTCCCCTGCACATTCAGT-3' \\
& Reverse & 5'-CTGGGCCAACAGTCTCATGT-3' \\
\multirow{3}{*}{ 3-Arrestin } & Forward & 5'-GGGCATTTGTACTGAGCTGT-3' \\
& Reverse & 5'-TGCACCTTGAGGCATCTCTG-3' \\
\multirow{3}{*}{ 3-Actin } & Forward & 5'-AGGGAAATCGTGCGTGACAT-3' \\
& Reverse & 5'-GAACCGCTCATTGCCGATAG-3' \\
\hline
\end{tabular}


The TCMs were purchased from Beijing Tongrentang TCM Chain Drug Store (Chengdu, China). They were authenticated by Professor Min Li (Department of Pharmacognosy, College of Pharmacy, Chengdu University of TCM, Chengdu, China). After decocting 3 times (each for $1 \mathrm{~h}$ ), the total extracts were filtered and subsequently dried in vacuum at $55^{\circ} \mathrm{C}$ to obtain the GHX extract (yield was approximately $10 \%$ ). The dose of GHX used $(375 \mathrm{mg} / \mathrm{kg}$ ) in this research was estimated from its clinical dose.

\section{Experimental protocols and animal model preparation}

A total of 40 rats were randomly divided into 4 groups ( $=10)$ : 1) normal group, 2) model group (control group), 3) positive treatment group [treated with aminophylline (ANP)], 4) GHX treatment group $(375 \mathrm{mg} / \mathrm{kg})$. Except for the normal rats, all animals in control and positive groups were treated with OVA to induce allergic asthma (AA) rats according to previously described methods with minor modifications [4]. Rats were immunized via intraperitoneal injection (ip) of $1 \mathrm{~mL}$ OVA- aluminum hydroxide mixture (1 $\mathrm{mg}$ OVA and $200 \mathrm{mg}$ aluminum hydroxide were dissolved in $1 \mathrm{~mL}$ saline) on days 0 and 7 . Thereafter, the rats were activated with $1 \%$ OVA-saline solution by aerosol inhalation in a glass box $(10 \mathrm{~cm} \times 10 \mathrm{~cm} \times 20 \mathrm{~cm})$ from 14 to 21 days (30 $\mathrm{min} /$ day). Rats in the normal group were subjected to the same procedure, but with saline in place of OVA and aluminum hydroxide mixture. In the positive and GHX treatment rats, ANP $(300 \mathrm{mg} / \mathrm{kg})$ and $\mathrm{GHX}(375 \mathrm{mg} / \mathrm{kg})$ were administered orally from $14^{\text {th }}$ to $21^{\text {st }}$ day. On day 21, pulmonary functions were determined, and after that, the rats were sacrificed under anesthesia using pentobarbital sodium (45 $\mathrm{mg} / \mathrm{kg}, i p)$ after collection of blood samples and bronchoalveolar lavage fluids (BALF). The lung tissues were excised for the following biochemical assays $[14,15]$.

\section{Determination of pulmonary functions}

Pulmonary functions (respiratory rate and airway hyperreactivit) were determined using a Buxco Animal Pulmonary Function analysis system (FinePointe ${ }^{\text {TM }}$ NAM, Data Sciences International Inc, St. Paul, MN, USA).

\section{Blood cell count}

Blood smears were prepared and fixed with formalin. Wright-Giemsa staining was performed, and subsequently the cell counts was carried out under an optical microscope (Olympus $2 \mathrm{H} 12003$, Tokyo, Japan).

\section{Assay of sigA, IgE, IL-4 and IFN-y by ELISA}

The levels of slgA and IgE in BALF and levels of $\mathrm{IL}-4$ and IFN- $\mathrm{Y}$ in serum were determined by commercial ELISA kits according to the manufactures' instructions. Absorbance was read at $450 \mathrm{~nm}$ in a micro-plate reader (Thermo Mulliskan Ascant 413MBY042078, Waltham, MA, USA).

\section{Real-time PCR (qRT-PCR) assay}

Lung tissues obtained from each rat were separately homogenized, and total RNA extracted with Trizol reagent. Subsequently, the total RNA was used for synthesis of cDNA for GATA-3, T-bet, TRL-2, TRL-4, MyD88, $\beta$-arrestin and $\beta$-actin with reverse transcription by using qRT-PCR (CFX96TM Real-Time System, BioRad, Hercules, CA, USA). The mRNA primers used in the real-time PCR experiments are shown in Table 1. Reverse transcription was performed according to the manufacturer's instructions on the commercial kits for the quantitative real-time RT-PCR reaction.

\section{Statistical analysis}

Data are expressed as mean \pm standard deviation (SD). Statistically significant differences were analyzed using two-tailed Student's $t$-test using SPSS 13.0 (SPSS Inc., Chicago, IL, USA). $P<0.05$ was considered to indicate a statistically significant difference.

\section{RESULTS}

\section{Pulmonary function}

Compared with normal rats, the respiratory rate $(p<0.01)$ and penh value $(p<0.01)$ of the allergic asthma model rats were significantly increased. However, similar to positive drug treatment, GHX $(375 \mathrm{mg} / \mathrm{kg})$ significantly reversed the increases in respiratory rate $(p<$ $0.01)$ and Penh value $(p<0.05)$ when compared with the control rats (Figure 1).

\section{Blood cell count}

Eosinophils, neutrophils, lymphocytes and monocytes are significantly increased in the allergic asthma control rats when compared to normal rats $(p<0.01$, Table 1$)$. In contrast, the positive treatment reversed the increases in these inflammatory cells $(p<0.01, p<0.01, p<$ 0.05 and $p<0.01$, respectively). Similar to the positive drug, GHX $(375 \mathrm{mg} / \mathrm{kg})$ treatment also resulted in significant decreases in all the four 
Table 2: Blood cell count $\left(\times 10^{6} / \mathrm{L}\right)$

\begin{tabular}{lcccc}
\hline Group & Eosinophils & Neutrophils & Lymphocytes & Monocytes \\
\hline Normal & $2.66 \pm 1.20$ & $22.50 \pm 5.50$ & $37.00 \pm 5.00$ & $2.00 \pm 0.36$ \\
Control & $27.75 \pm 2.19 \# \#$ & $41.85 \pm 1.92 \# \#$ & $68.50 \pm 3.52 \# \#$ & $5.33 \pm 0.88 \# \#$ \\
Positive & $3.28 \pm 0.47^{* *}$ & $29.00 \pm 1.15^{\star *}$ & $55.00 \pm 2.30^{*}$ & $2.88 \pm 0.26^{\star *}$ \\
$375 \mathrm{mg} / \mathrm{kg}$ & $2.37 \pm 0.37^{* *}$ & $23.00 \pm 3.60^{* *}$ & $30.33 \pm 3.77^{* *}$ & $2.66 \pm 0.88^{* *}$ \\
\hline
\end{tabular}

Aminophylline (300 mg/kg) was used as positive drug. Data presented as mean $\pm S D(n=10) ;{ }^{\star} p<0.05,{ }^{\star *} p<$ 0.01 , vs. control rats; $\# \# p<0.01$, vs. normal rats
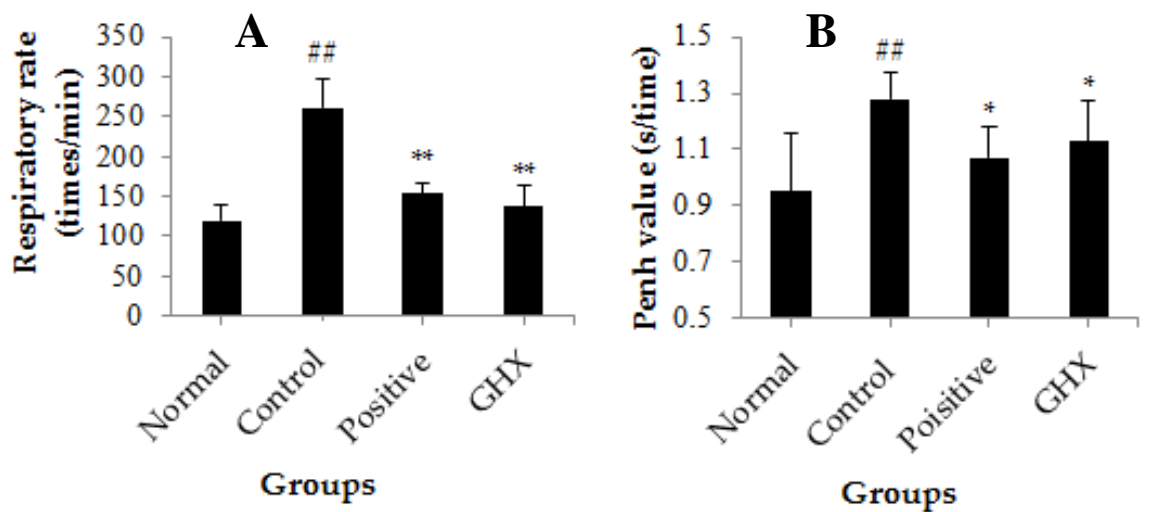

Figure 1: Respiratory rate (A) and Penh value (B). Aminophylline (300 mg/kg) was used as positive drug. Data

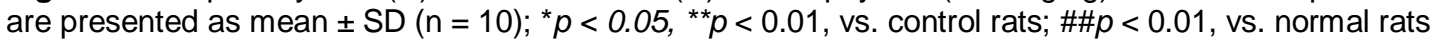
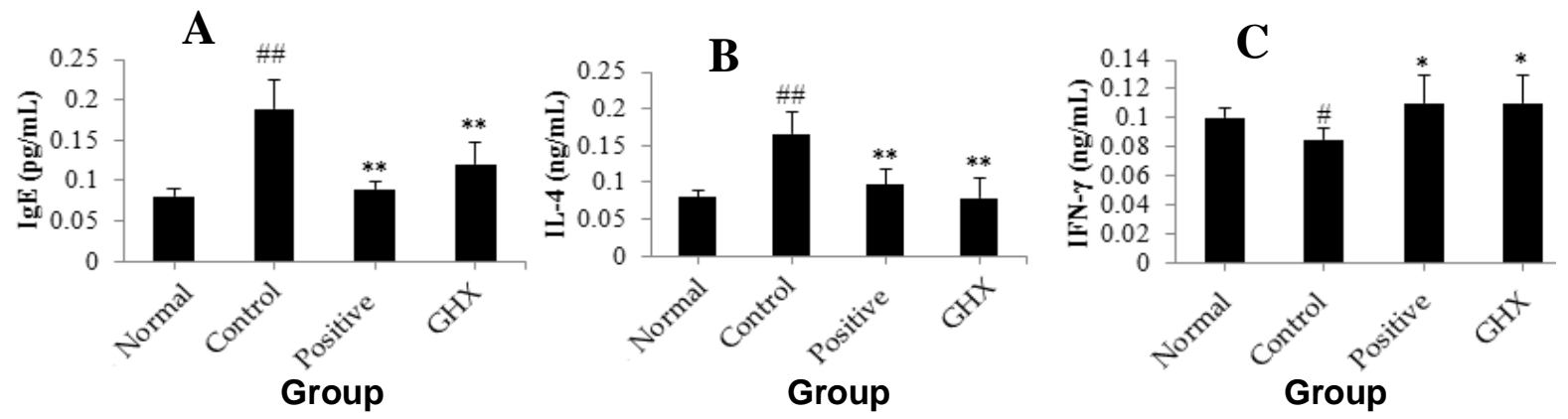

Figure 2: ELISA assays for $\lg E$ in serum (A), and IL-4 (B) and IFN-Y (C) in BALF. Aminophylline (300 mg/kg) was used as the positive drug. Data are presented as mean $\pm \operatorname{SD}(\mathrm{n}=10) ;{ }^{*} p<0.05$, ${ }^{* *} p<0.01$, vs. control rats; $\# \#<0.01$, vs. normal rats

blood cell counts relative to corresponding values for control rats $(p<0.01)$.

\section{Levels of IgE in serum and IL-4 and IFN-y in BALF}

As shown in Figure $2 \mathrm{~A}$, serum IgE was sharply increased $(p<0.01)$ when compared to normal rats. After treatment with positive drugs $(p<$ $0.01)$ and $\mathrm{GHX}(375 \mathrm{mg} / \mathrm{kg})$, level of $\mathrm{lgE}$ was significantly decreased $(p<0.01)$ when compared to that of control rats. After induction with OVA, the IL-4 levels $(p<0.01$, Figure $2 B)$ of control rats were significantly increased whereas IFN-y $(p<0.01$, Figure $2 \mathrm{C})$ was significantly decreased. For the positive treated rats, the IL-4 $(p<0.01$, Figure 2B) was significantly decreased and the IFN-y $(p<0.01$, Figure $2 \mathrm{C})$ was significantly increased compared with the control rats. Importantly, GHX treatment showed similar results to the positive drugs, and IL-4 levels in
BALF were significantly decreased by treatment with $\mathrm{GHX}(375 \mathrm{mg} / \mathrm{kg})(p<0.01$, Figure 2B) whereas the IFN- $\gamma$ levels were significantly increased by GHX at the dose of $375 \mathrm{mg} / \mathrm{kg}(p<$ 0.05 , Figure $2 \mathrm{C}$ ).

\section{mRNA expressions of GATA-3, TRL-2, TRL-4, MyD88, TRAF6 and $\beta$-arrestin}

As shown in Figure 3, the mRNA expressions of GATA-3 $(p<0.01)$, TRL-2 $(p<0.01)$, TRL-4 $(p<$ $0.01)$, MyD88 $(p<0.01)$, TRAF6 $(p<0.01)$ and $\beta$ arrestin $(p<0.01)$ were significantly up-regulated in the lung tissues whereas that of T-bet $(p<$ 0.01 )was significantly down-regulated when compared with normal rats. Interestingly, the positive treatment and GHX (375 mg/kg) brought about significant decreases in the mRNA expressions of GATA-3 ( $p<0.01)$, TRL-2 $(p<$ $0.01)$, TRL-4 $(p<0.01)$, MyD88 $(p<0.01)$, TRAF6 $(p<0.01)$ and $\beta$-arrestin $(p<0.01)$ in 

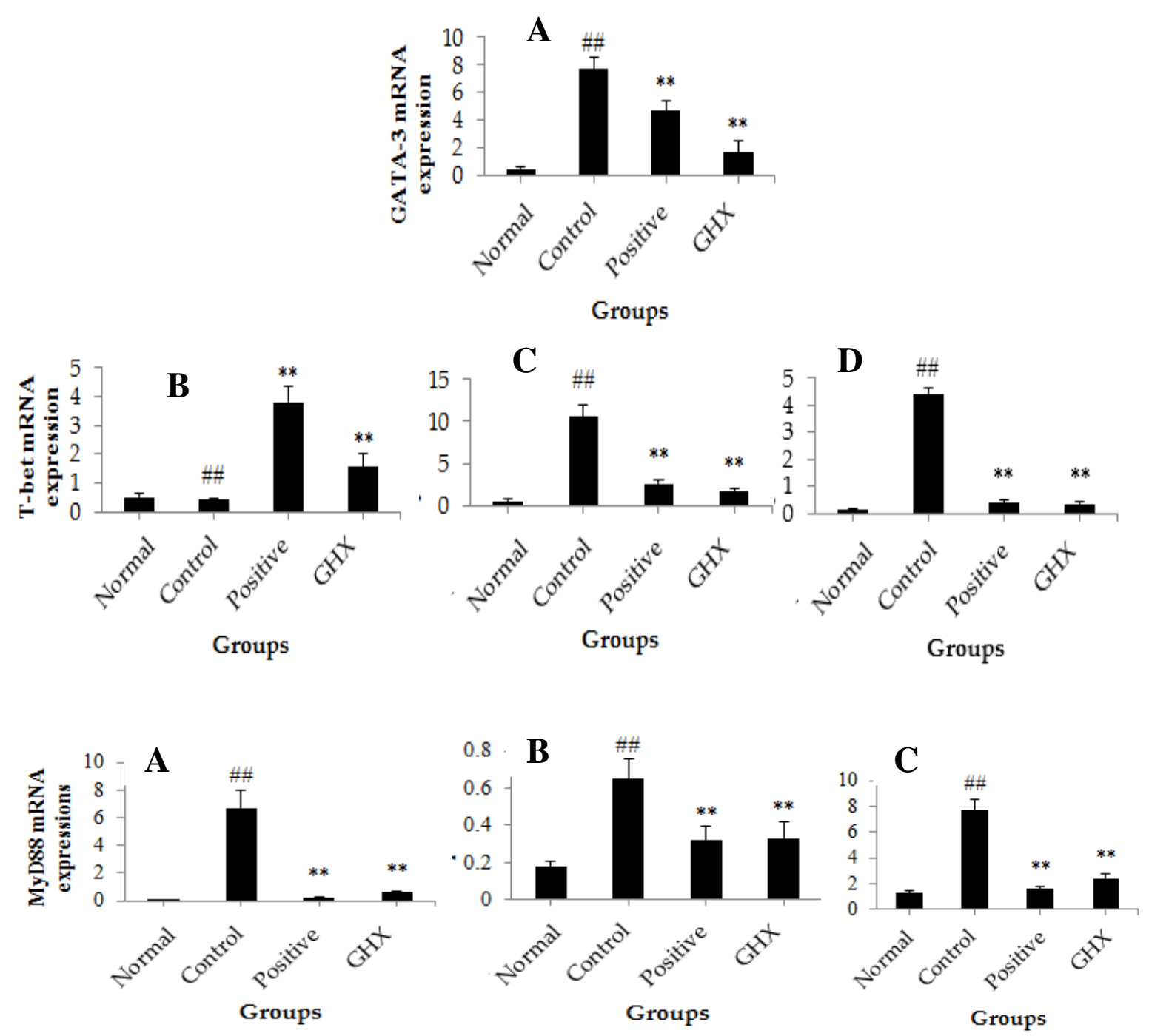

Figure 3: mRNA expressions of (a) GATA-3, T-bet, TLR-2 and TLR-4 and (b) MyD88, TRAF6 and $\beta$-arrestin. Aminophylline $(300 \mathrm{mg} / \mathrm{kg})$ was used as the positive drugs. Data presented as Mean $\pm \mathrm{SD}(\mathrm{n}=10) ;{ }^{* *} p<0.01$, vs. control rats; \#\#p<0.01, vs. normal rats

lung tissues, when compared with control rats. However, mRNA expression of T-bet was upregulated by treatment with $\mathrm{GHX}$ at the dose of $375 \mathrm{mg} / \mathrm{kg}(p<0.01)$ relative to control rats.

\section{DISCUSSION}

The establishment of a suitable animal model is the first and most crucial step in investigating the therapeutic effects of candidate drugs [16]. In the present investigation, an allergic asthma rat animal model was successfully prepared by induction with OVA. The results showed that the model rats manifested obvious features of allergic asthma, which were reflected in the results of pulmonary functions and inflammatory blood cell counts. The results also demonstrated that GHX has potential therapeutic effect against OVA-induced allergic asthma based on the rat model. $\lg \mathrm{E}$ is usually expressed in allergic asthma patients, due probably to their high mucosal immune responses $[17,18]$. In the present research, GHX significantly decreased the serum levels of $\operatorname{lgE}$ in the asthmatic rats. In allergic asthma patients, infiltrated inflammatory cells over-release IL-4, which aggravates airway inflammatory reactions. In addition, IFN- $y /$ IL-4 ratio is a reflection of the proportion of Th1 and Th2. Increases in IFN- $\gamma$ are beneficial to asthma patients. The present results show that GHX decreased the level of IL-4 and increased the level of IFN- $y$ in BALF [19-21]. Just like IFN- $y /$ IL4 ratio, T-bet/GATA-3 ratio can also be considered a measure of Th1/Th2 cytokine profiles. Studies have shown that allergic asthma results from lymphocyte proliferation of allergenspecific type 2 T-helper (Th2) with over-release of Th2 cytokines such as IL-4, IL-5, IL-13 and IL$25[19,22]$. Thus, increases in T-bet/GATA-3 ratio would be beneficial for treating allergic asthma. Toll-like receptors (TLRs) are membrane-located 
pattern recognition receptors closely related to immunocompetence [23,24]. TLRs can recognize specific conserved molecular components of microorganisms and then transfer the signals into the cell, leading to the activation of NF-KB $[25,26]$.

The typical pathological changes in asthma are airway inflammatory reactions and airway remodeling. TLRs play important roles in the development of airway inflammatory reactions, and activation of the MyD88- IRAK-TRAF6-IKKNF-KB signal pathway [27]. In addition, TLRs promote not only the maturity and differentiation of immune cells but also the conversion of $C D^{4+}$ $T$ cells into $T$-regulatory cells ( $T r$ cells). Thus, TLRs-NF-kB signal pathway also regulatesTh1/Th2 ratio via $\operatorname{Tr}$ cells [28]. It has been reported that TLR-2 and TLR-4 are closely related to the re-organizations of peptidoglycan and lipopolysaccharides (LPS), respectively.

The $\beta$-arrestin influences the functions of $T$ cells in several ways, and is up-regulated in allergic asthma patients [29]. The present research shows that the expressions of TRL-2, TRL-4, MyD88, TRAF6 and $\beta$-arrestin mRNAs were significantly up-regulated in lung tissues of the model rats. Interestingly, the GHX treatment significantly decreased the expressions of mRNAs of these genes in lung tissues.

\section{CONCLUSION}

The findings of this study demonstrate that GHX possesses potentials for application in the treatment of allergic asthma, most likely $v$ regulation of TLRs signal pathway in rats. However, additional investigations are required to determine the suitability of GHX in the clinical treatment of allergic diseases.

\section{DECLARATIONS}

\section{Acknowledgement}

The authors are grateful for the financial support received from National Natural Science Foundation of China (no. 81303085) and Foundation of Science \& Technology Department of Sichuan Province (no. 2013JY0067).

\section{Conflict of Interest}

No conflict of interest associated with this work.

\section{Contribution of Authors}

The authors declare that this work was done by the authors named in this article and all liabilities pertaining to claims relating to the content of this article will be borne by them.

\section{Open Access}

This is an Open Access article that uses a funding model which does not charge readers or their institutions for access and distributed under the terms of the Creative Commons Attribution License (http://creativecommons.org/licenses/by/ 4.0) and the Budapest Open Access Initiative (http://www.budapestopenaccessinitiative.org/rea d), which permit unrestricted use, distribution, and reproduction in any medium, provided the original work is properly credited.

\section{REFERENCES}

1. Julia V, Macia L, Dombrowicz D. The impact of diet on asthma and allergic diseases. Nat Rev Immunol 2015; 15: 308-322.

2. Zhu J, Song J, Liu Z, Han J, Luo H, Liu Y, Jia Z, Dong Y, Zhang $W$, Jiang $F$, et al. Association between allergic conditions and risk of prostate cancer: A PrismaCompliant Systematic Review and Meta-Analysis. Sci Rep 2016; 6: 35682.

3. Yacoub MR, Colombo G, Marcucci F, Caminati M, Sensi L, Di Cara G, Frati F, Incorvaia C. Effects of sublingual immunotherapy on allergic inflammation: an update. Inflamm Allergy Drug Targets 2012; 11: 285-291.

4. Lee $M Y$, Shin IS, Jeon WY, Lim HS, Kim JH, Ha H. Pinellia ternata Breitenbach attenuates ovalbumininduced allergic airway inflammation and mucus secretion in a murine model of asthma. Immunopharmacol Immunotoxicol 2013; 35: 410-418.

5. Masoli M, Fabian D, Holt $S$, Beasley $R$. The global burden of asthma: Execurive summary of the GINA Dissemination Committee report. Allergy 2004; 59: 469478.

6. Liu Z, Zhang XH, Callejas-Díaz B, Mullol J. MicroRNA in United Airway Diseases. Int J Mol Sci 2016; 17: 716.

7. Santus $P$, Radovanovic D. Prostaglandin D2 receptor antagonists in early development as potential therapeutic options for asthma. Expert Opin Investig Drugs 2016; 25: 1083-1092.

8. Li HJ, Kang SL, Li L. The progress of anti-asthma drugs. Chin J Pharmacoepidemiol 2005; 14: 272-275.

9. Strachan DP. Family size, infection and atopy: the first decade of the "hygiene hypothesis". Thorax 2000; 55: 2-10

10. Chellaih P, Sivadas G, Chintu S, Vaishnavi Vedam VK, Arunachalam $R$, Sarsu M. Effect of anti-asthmatic drugs on dental health: A comparative study. J Pharm Bioallied Sci 2016; 8: S77-S80.

11. Liu JC. Research of Guizhijiahoupu decoction jiajian on 78 clinical samples of allergic asthma. Asia Pacific Trad Med 2015; 11: 133-134.

Trop J Pharm Res, May 2017; 16(5): 1178 
12. Zhang YZ, Nie HM, Zhang N, He W, Yu ST, Hu Y. Effects of Guizhijiahoupuxingzi tang jiawe on the change of TNF- $\alpha, E T-1$ in the cobaya of allergic asthma. J Beijing Univ Tradit Chin Med 2000; 23: 23-24.

13. U.S. Office of Science and Technology Policy. Laboratory animal welfare, U.S. government principles for the utilization and care of vertebrate animals used in testing, research and training; notice. Fed Regist 1985; 50 : 20864-20865.

14. Jang $T Y$, Jung AY, Kim YH. Hormetic effect of chronic hypergravity in a mouse model of allergic asthma and rhinitis. Sci Rep 2016; 6: 27260.

15. Shin D, Park SH, Choi YJ, Kim YH, Antika LD, Habibah NU, Kang MK, Kang YH. Dietary Compound kaempferol inhibits airway thickening induced by allergic reaction in a bovine serum albumin-induced model of asthma. Int $J$ Mol Sci 2015; 16: 29980-29995.

16. Xu L. Animal models of human diseases. Zoological Research 2011; 32: 1-3.

17. Mantis NJ1, Rol N, Corthésy B. Secretory IgA's complex roles in immunity and mucosal homeostasis in the gut. Mucosal Immunol 2011; 4: 603-611.

18. Peng W, Ming QL, Han P, Zhang QY, Jiang YP, Zheng CJ, Han T, Qin LP. Anti-allergic rhinitis effect of caffeoylxanthiazonoside isolated from fruits of Xanthium strumarium L. in rodent animals. Phytomedicine 2014; 21: 824-829.

19. Lee MY, Shin IS, Jeon WY, Lim HS, Kim JH, Ha H. Pinellia ternata Breitenbach attenuates ovalbumininduced allergic airway inflammation and mucus secretion in a murine model of asthma. Immunopharmacol Immunotoxicol 2013; 35: 410-418.

20. Swain SL, Weinberg AD, English M, Huston G. IL-4 directs the development of Th2-like helper effectors. $J$ Immunol 1990; 145: 3796-3806.

21. Lee BJ, Moon HG, Shin TS, Jeon SG, Lee EY, Gho YS, Lee CG, Zhu Z, Elias JA, Kim YK. Protective effects of basic fibroblast growth factor in the development of emphysema induced by interferon- $y$. Exp Mol Med 2011; 43: 169-178.

22. Lin $Y$, Zhou X, Guo W, Li Q, Pan X, Bao Y, He M, Zhu B, Lin $X$, Jin L. RhIL-11 treatment normalized Th1/Th2 and T-bet/GATA-3 imbalance in in human immune thrombocytopenic purpura (ITP). Int Immunopharmacol 2016; 38: 40-44.

23. Shin HS, See HJ, Jung SY, Choi DW, Kwon DA, Bae MJ, Sung $K S$, Shon DH. Turmeric (Curcuma longa) attenuates food allergy symptoms by regulating type 1/type 2 helper $T$ cells (Th1/Th2) balance in a mouse model of food allergy. J Ethnopharmacol 2015; 175: 21 29.

24. Duffy L, O'Reilly SC. Toll-like receptors in the pathogenesis of autoimmune diseases: recent and emerging translational developments. Immuno Target Ther 2016; 5: 69-80.

25. Lei $W$, Browning JD Jr, Eichen $P A, L u C H$, Mossine $V V$, Rottinghaus GE, Folk WR, Sun GY, Lubahn $D B$, Fritsche KL. Immuno-stimulatory activity of a polysaccharide-enriched fraction of Sutherlandia frutescens occurs by the toll-like receptor-4 signaling pathway. J Ethnopharmacol 2015; 172: 247-253.

26. Achek A, Yesudhas D, Choi S. Toll-like receptors: promising therapeutic targets for inflammatory diseases. Arch Pharm Res 2016; 39: 1032-1049.

27. Im EJ, Kim SJ, Hong SB, Park JK, Rhee MH. AntiInflammatory Activity of Bee Venom in BV2 Microglial Cells: Mediation of MyD88-Dependent NF-KB Signaling Pathway. Evid Based Compl Alt Med 2016; 2016: 3704764.

28. Flaherty S, Reynolds JM. TLR Function in Murine CD4 (+) $T$ Lymphocytes and Their Role in Inflammation. Method Mol Biol 2016; 1390: 215-227.

29. Walker JK, Fong AM, Lawson BL, Savov JD, Patel DD, Schwartz DA, Lefkowitz RJ. Beta-arrestin-2 regulates the development of allergic asthma. J Clin Invest 2003; 112: $566-574$. 